\title{
Pediatric palliative care: data of the first 13 months of operation
}

\author{
๑1)Fatma Zehra Öztek Çelebi, @Şanlıay Şahin \\ Health Sciences University, Dr. Sami Ulus Maternity and Children's Training and Research Hospital, Departments of Pediatrics, Ankara, Turkey
}

Cite this article as: Öztek Çelebi FZ, Şahin Ş. Pediatric palliative care: data of the first 13 months of operation. J Health Sci Med 2021; 4(5): 656-661.

\begin{abstract}
Aim: Children with complex chronic conditions are main candidates for pediatric palliative care (PPC). Despite the proven advantages of palliative care for these children, the literature lacks on the adequate description of the pediatric population receiving this care. The aim of this study was to describe demographic characteristics of the patients, to examine the patient survival and the factors affecting patient survival. To our knowledge, this is the first description of the cohort of children and adolescents on PPC in Turkey.

Material and Method: This retrospective chart review study examined patients receiving palliative care at Health Sciences University, Dr. Sami Ulus Maternity and Children's Training and Research Hospital and Children's Training and Research Hospital between 2.12.2019 and 31.12.2020. The data of demographics, underlying diagnosis, medical technology dependence, symptoms at admission, number of hospitalizations, number of emergency department (ED) admissions were collected.

Results: 70 male and 66 female patients were admitted 259 times during the observation period. The median length of hospital stay was 7 days. Median age at referral was 44 months (range:2.7-215). Fifty-one patients (37.5\%) were younger than 2 years of age. Neurological diseases were the most prevalent disease group. 56 of our patients (41\%) had a tracheostomy. 82 patients $(60.3 \%)$ needed respiratory support. Fifty of them were ventilated through home-type mechanical ventilator. Only 28 patients $(20.6 \%)$ could be fed through oral route. Nasogastric tube $(n=84,61.8 \%)$ was the main device used by children who needed nutritional support. 52\% of patients were referred from ED. Most prevalent symptoms of the patients at admission were dyspnea and tachypnea. 151 of the patients $(58.3 \%)$ were diagnosed with infection, the most common infection was lower respiratory tract infection $(\mathrm{n}=103,39.8 \%)$. Of 259 PPC center admissions 224 (86.5\%) were discharged to home. Twenty-seven children $(20 \%)$ died during study period. Nineteen of deceased patients died in intensive care unit (70\%). The 1-year survival rate of the patients was $78.1 \%$. In logistic regression analysis the risk of death was 3.4 times higher in patients $\leq 2$ years of age (CI: 1.4-8.8, $\mathrm{p}=0.01$ ) and in patients with respiratory support (CI: 1.1-11.0, $\mathrm{p}=0.04)$.

Conclusion: Describing the cohort of patients on PPC provides important information on the complexity of their disease process, types of their illnesses, medical technology dependence, re-admission rates, mortality status and factors affecting mortality. Important research has been done but pediatric palliative care is still in infancy in Turkey. Future prospective research is needed to understand the unique challenges of PPC.
\end{abstract}

Keyword: End of life, medical devices, multiple chronic health conditions, survival

\section{INTRODUCTION}

With the improvement of medical science and care, a growing number of children are living with complex and often life-limiting chronic conditions (1). Children with complex chronic conditions (CCC), including cancer, congenital conditions, neuromuscular, hematological diseases, necessitate the use of multiple therapies and patients with these conditions represent the main pediatric candidates for palliative care (2). These children require intense medical and nursing care in the home and often lengthy hospital stays. Earlier

studies found that palliative care results in higher parent satisfaction, better symptom management, higher quality of life, and often longer life; however, the current literature about adequate description of the pediatric population receiving this care is scarce (3-7).

We examined data from all children referred to pediatric palliative care (PPC) center from 2 December 2019 to 31 December 2020, at one children's hospital in Ankara. The palliative care program at this hospital began in $2^{\text {th }}$ December 2019. The center provides 
24/7 in-hospital care. The purpose of this study was to describe demographic characteristics, to describe the types of illnesses that resulted in referral, to examine the patient survival following referral to palliative care and to examine the relationship between patient survival and key clinical and sociodemographic variables. To our knowledge, this is the first description of the cohort of children and adolescents on PPC in Turkey.

\section{MATERIAL AND METHOD}

\section{Research Design}

This retrospective chart review study examined patients receiving palliative care at Health Sciences University, Dr. Sami Ulus Maternity and Children's Training and Research Hospital during a 13-months period. A cohort was created by examining records of all patients referred to PPC center during the study period from December 2, 2019, through December 31,2020. Children were included in the cohort if they were between the ages of 1 month and 18 years when they received the referral to PPC.

\section{Procedures}

Inpatient data were retrieved from the electronic medical record of our hospital. All data were identified before analysis. The study was approved by the Dr. Sami Ulus Maternity and Children's Training and Research Hospital Clinical Researchs Ethics Committee (Date: 04.02.2021, Decision No: E-21/02-96). The study was conducted in accordance with the principles of the Declaration of Helsinki.

\section{Measurement}

The data collected included gender, date of birth, date of death, date of referral to palliative care, underlying diagnosis, technology dependence, symptoms at admission, the date of hospitalization, the date of discharge, the reason for hospitalization, therapies during hospitalization, the number of hospitalizations during the study period, the number of ED admissions, and the number of home health care admission.

Children were grouped based on their ages into 4 groups: ages 0 to 2 years, ages 3-5 years, ages $6-10$ years, and ages 11-18 years. The underlying diagnoses were collapsed into categories as neurological disorders, metabolic disorders, syndromes, cardiological disorders, prematurity and other according to Feudtner's CCC categories (2). The cause of PPC center admission was grouped as training/ adaptation for new medical condition of the children, lower respiratory system infections, sepsis, increased seizure frequency, other infections, gastrointestinal system problems, electrolyte and kidney function disorders and other conditions. The primary outcome variable was the total number of days from referral to palliative care until death or the end of the study. Right censoring occurred if a child survived beyond the end of the study period. For children who survived beyond the end of the study period, the total number of days was calculated using the end of the study (December 31, 2020).

\section{Data Analyses}

All data analyses were conducted using IBM SPSS Statistics v20 with $\mathrm{p}<0.05$ as the significance level. Descriptive statistics were computed to characterize the sample, including gender and age distribution, survival status, and admission reason. Comparison of binary variables was performed with the Chi square test. Continuous values were expressed as median [min-max, interquartile range (IQR)]. Kaplan-Meier estimation was used to estimate the survival function during study period using first admission to PPC center as starting point. Group comparison was performed with log-rank test. Logistic regression model was used to find the factors affecting death and hospital readmissions.

\section{RESULTS}

\section{Demographic and Clinical Properties of the Cohort}

In the study period, the PPC center cared for 136 patients. Seventy (51.5\%) patients were male. Median age at referral was 44 months (min:2.7 max:215, IQR:97.3 months). Fifty-one patients (37.5\%) were younger than 2 years of age. Neurological diseases were the most prevalent disease group. Place of residency of fifty-one patients (37.5\%) was outside Ankara. Table 1 shows demographic variables of the patients. 56 of our patients $(41 \%)$ had a tracheotomy. 82 patients $(60.3 \%)$ needed respiratory support. Fifty of them were ventilated through home type mechanical ventilator. Only 28 patients $(20.6 \%)$ could be fed through oral route. Nasogastric tube $(n=84$, $61.8 \%$ ) was the main device used by children who needed nutritional support (Table 1).

\section{Hospital Admissions}

136 patients were admitted 259 times in total. The median length of hospital stay was 7 days (min:1, max:108 IQR:22 days). Fifty-one patients (37.5\%) had more than once PPC center admissions. Only six admissions were planned for symptom control by PPC team. Other admissions were referred to PPC center from emergency departments (ED), intensive care units (ICU) or from other inpatient services. More than half of the admissions $(n=135$, 52.1\%) were referred from ED. Table 2 demonstrates the clinical characteristics of all admissions. Most prevalent symptoms of the patients at admission were dyspnea/ tachypnea/low oxygen saturation in 85 patients $(32.8 \%)$ and fever in 81 patients (31.3\%) (Table 2). Most of the patients $(n=151,58.3 \%)$ were diagnosed with infection, the most common infection was lower respiratory tract 
infection ( $\mathrm{n}=103,39.8 \%)$ (Table 2). Antibiotics were used in 206 (79.5\%) admissions. More than one antibiotic was administered in 150 admissions. In 82 admissions antiepileptics of the patients were revised. Oral opioids (morphine) were started only in 3 patients.

\begin{tabular}{|c|c|}
\hline & $\mathrm{N}=136$ \\
\hline Female/male & $70 / 66$ \\
\hline Median age (month) (IQR) & $44(97.3)$ \\
\hline \multicolumn{2}{|l|}{ Age groups } \\
\hline $0-2$ years age group & $51(37.5 \%)$ \\
\hline $3-5$ years age group & $25(18.4 \%)$ \\
\hline $6-10$ years age group & $36(26.5 \%)$ \\
\hline$>11$ years age group & $24(17.6 \%)$ \\
\hline \multicolumn{2}{|l|}{ Underlying diseases } \\
\hline Neurological disorders (n, \%) & $72(52.9 \%)$ \\
\hline Epilepsy & 23 \\
\hline Cerebral palsy & 21 \\
\hline Central nervous system malformations & 14 \\
\hline Neurodegenerative disease & 5 \\
\hline Spinal muscular atrophy & 3 \\
\hline Demyelination disorders & 6 \\
\hline Metabolic disorders (n, \%) & $34(25 \%)$ \\
\hline Amino acid metabolism disorders & 9 \\
\hline Mitochondrial diseases & 7 \\
\hline Lysosomal storage disorders & 6 \\
\hline Fatty acid oxidation disorders & 4 \\
\hline Glycogen storage diseases & 2 \\
\hline Urea cycle disorders & 2 \\
\hline Mucopolysaccharidoses & 2 \\
\hline Rare metabolic disorders & 2 \\
\hline Syndromes $(\mathrm{n}, \%)$ & $19(14 \%)$ \\
\hline Down syndrome & 3 \\
\hline Jeune syndrome & 2 \\
\hline Miscellaneous & 14 \\
\hline Cardiovascular disorders (n, \%) & $5(3.7 \%)$ \\
\hline Ventricular septal defect & 2 \\
\hline Tetralogy of Fallot & 2 \\
\hline Coarctation of the aorta & 1 \\
\hline Prematurity (n, \%) & $4(2.9 \%)$ \\
\hline Other disorders $(\mathrm{n}, \%)$ & $2(1.5 \%)$ \\
\hline Immune deficiencies & 1 \\
\hline Primary ciliary dyskinesia & 1 \\
\hline \multicolumn{2}{|l|}{ Place of residency } \\
\hline Ankara & $85(62.5 \%)$ \\
\hline Outside Ankara & $51(37.5 \%)$ \\
\hline \multicolumn{2}{|l|}{ Status of having respiratory support } \\
\hline No respiratory support & $54(39.7 \%)$ \\
\hline Respiratory support via free flow oxygen & $23(16.9 \%)$ \\
\hline $\begin{array}{l}\text { Respiratory support via Bilevel Positive Airway } \\
\text { Pressure }\end{array}$ & $9(6.6 \%)$ \\
\hline $\begin{array}{l}\text { Respirator support via home-type mechanical } \\
\text { ventilator }\end{array}$ & $50(36.8 \%)$ \\
\hline \multicolumn{2}{|l|}{ Status of having nutritional support } \\
\hline No nutritional support & $28(20.6 \%)$ \\
\hline Nutritional support via nasogastric tube & $84(61.8 \%)$ \\
\hline Nutritional support via gastrostomia & $24(17.6 \%)$ \\
\hline
\end{tabular}

\begin{tabular}{|c|c|}
\hline Total hospital admissions & $\mathrm{N}=259$ \\
\hline \multicolumn{2}{|l|}{ The patient was referred to PPC center from ${ }^{*}$} \\
\hline Emergency Department & $135(52.1 \%)$ \\
\hline PICU & $62(23.9 \%)$ \\
\hline NICU & $7(2.7 \%)$ \\
\hline Other inpatient services & $49(18.9 \%)$ \\
\hline \multicolumn{2}{|l|}{ Number of admissions } \\
\hline 1 admission & $85(62.6 \%)$ \\
\hline 2 admissions & $22(16.3 \%)$ \\
\hline 3 admissions & $9(6.7 \%)$ \\
\hline 4 admissions & $9(6.7 \%)$ \\
\hline 5 admissions & $3(2.3 \%)$ \\
\hline 6 admissions & $3(2.3 \%)$ \\
\hline 8 admissions & $2(1.5 \%)$ \\
\hline 9 admissions & $2(1.5 \%)$ \\
\hline \multicolumn{2}{|l|}{ Prevalent symptoms of the patients at admission } \\
\hline dyspnea/tachypnea/low oxygen saturation & $85(32.8 \%)$ \\
\hline fever & $81(31.3 \%)$ \\
\hline irritability & $53(20.5 \%)$ \\
\hline convulsions & $42(16.2 \%)$ \\
\hline vomiting & $35(13.5 \%)$ \\
\hline increased spasticity & $27(10.4 \%)$ \\
\hline dysuria & $11(4.2 \%)$ \\
\hline diarrhea & $10(3.9 \%)$ \\
\hline edema & $6(2.3 \%)$ \\
\hline \multicolumn{2}{|l|}{ Causes of hospitalization in PPC patients ${ }^{\star}$} \\
\hline Lower respiratory tract infection & $103(39.8 \%)$ \\
\hline $\begin{array}{l}\text { training/adaptation of the family for new medical } \\
\text { condition of the children }\end{array}$ & $57(22 \%)$ \\
\hline Sepsis & $26(10 \%)$ \\
\hline Other infections (urinary tract infection, cellulitis) & $22(8.5 \%)$ \\
\hline Increased frequency of epileptic seizures & $21(8.1 \%)$ \\
\hline $\begin{array}{l}\text { Gastrointestinal system problems (vomiting, } \\
\text { diarrhea) }\end{array}$ & $19(7.3 \%)$ \\
\hline Electrolyte and kidney function test disorders & $6(2.3 \%)$ \\
\hline Other & $5(1.9 \%)$ \\
\hline
\end{tabular}

Of 259 PPC center admissions 224 (86.5\%) were discharged to home. Eighteen of them worsened during their PPC care admission and were transferred to intensive care. 13 of them were transferred to other hospitals. 4 of them died during their PPC care admission.

Fifty-one of the patients (37.5\%) had more than once PPC center admissions. Multiple PPC center admissions were more prevalent in patients $\leq 2$ years of age compared to patients $>2$ years of age ( $49 \%$ to $30.6 \%, p=0.03$ ). In logistic regression analysis being $\leq 2$ years of age, having respiratory or nutrition support did not affect having multiple PPC center admissions.

\section{Follow up and Patient Survival}

Median duration of care was 9.5 months (min:0.2 max:13, IQR:6.2 months). After their discharge from PPC center, 33 of our patients $(24.3 \%)$ were followed up by the home health services unit of our hospital. 58 (42.6\%) of our patients had no ED visit. 78 patients had at least one EDvisit. During the observation period, 11 patients $(8 \%)$ had more than ten ED visits. 
Twenty-seven children (20\%) died during study period. The majority of deceased patients died in intensive care unit $(\mathrm{n}=19,70 \%)$. The place of death was PPC center in 4 patients, ED in 2 patients and home in 2 patients. The 1 -year survival rate of our patients was $78.1 \%$. Figure 1 shows Kaplan-Meier Survival curve of our cohort. Median age at the time of death was 12.2 months (min:3.5, max:221.1; IQR:38.9 months). The mortality rate was significant higher in patients $\leq 2$ years of age compared to patients $>2$ years of age $(n=18,35.3 \%$ to $\mathrm{n}=9,10.6 \%)(\mathrm{p}<0.01) .1$-year survival of patients was $56.8 \%$ in patients $\leq 2$ years of age and $86.6 \%$ in patients $>2$ years of age $(\mathrm{p}<0.01)$ (Figure 2A). Oneyear survival was significant higher in patients without respiratory support than in patients with respiratory support $(87.1 \%$ to $68.1 \%$; $\mathrm{p}<0.01)$ (Figure $2 \mathrm{~B}$ ). In logistic regression analysis the risk of death was 3.4 times higher in patients $\leq 2$ years of age (CI: 1.4-8.8, $\mathrm{p}=0.01)$ and in patients with respiratory support (CI: $1.1-11.0, \mathrm{p}=0.04)$.

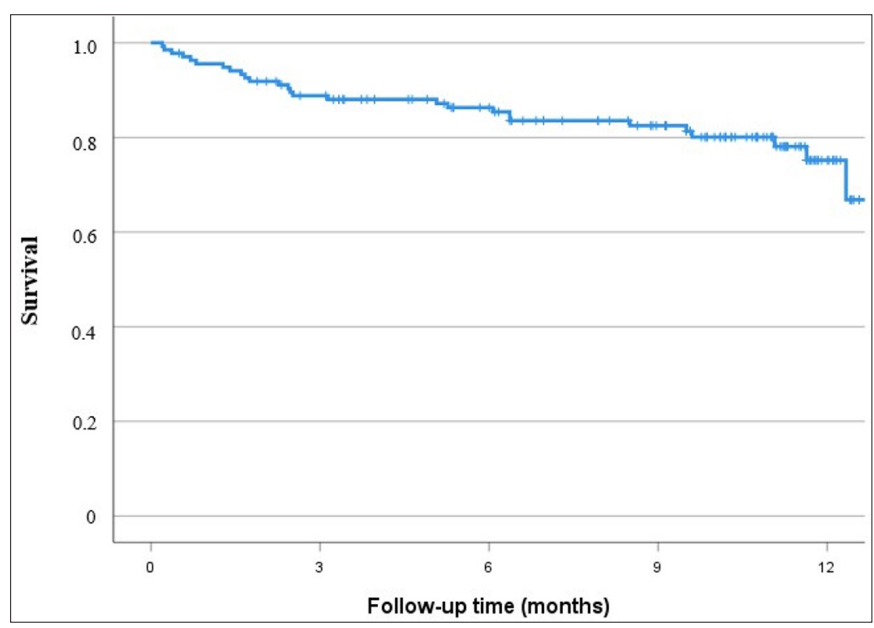

Figure 1. Kaplan-Meier Survival curve of the 136 patients.

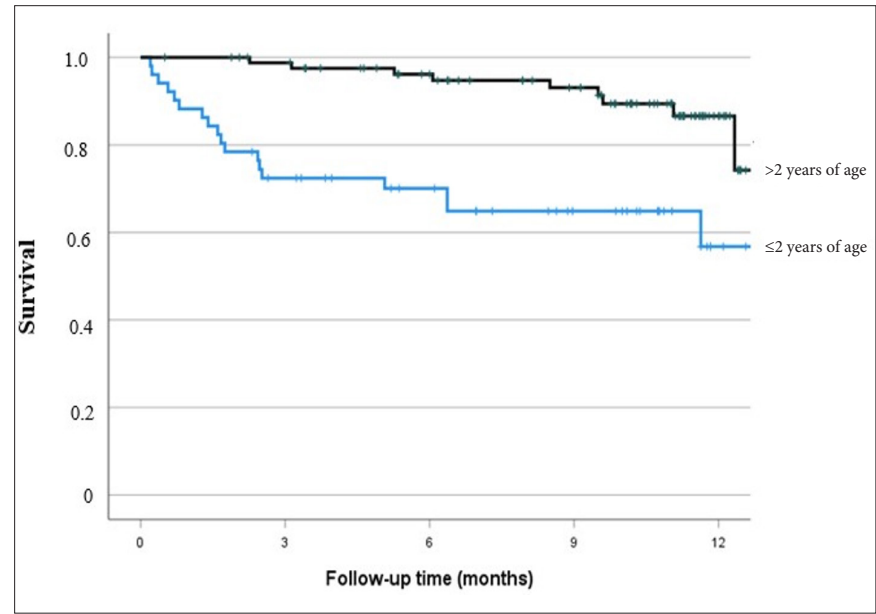

Figure 2A. Kaplan-Meier Survival curve of the 136 patients classified according to age. Patients who were $\leq 2$ years of age had significant worse survival than patients $>2$ years of age.

\section{DISCUSSION}

This study examined total hospitalizations in PPC centre of Dr. Sami Ulus Maternity and Children's Training and Research Hospital between December 2019 and December 2020. To our knowledge, this is the first survey in Turkey that defined the demographic and clinical characteristics of patients on PPC. We found that, the patients had high medical technology dependence, they admitted primarily to ED for their symptoms, had low utility of homehealth care services. Infections were the major cause of hospitalizations. One-fifth of the cohort died in the followup time. The place of death was ICUs in $70 \%$.

The most common underlying diagnoses seen in this study were neurologic and metabolic diseases. We had no malignancy patients that referred to our center. Consistent with our study, neurological conditions are reported to be the leading underlying diagnoses in the US $(8,9)$, the UK (10), Canada (11) and Italy $(12,13)$. The explanation of high rate of metabolic disease in this study could be the higher incidence of consanguine marriages in our country (14). The underrepresentation of malignancy children was noteworthy in this cohort. PPC is an emerging subspecialty in Turkey like the other developing countries in the world (15). We can speculate that the rate of malignancy patients will increase with the improved awareness of other pediatric subspecialties about PPC.

The high utilization of medical technology described in our study is much higher than other studies. Approximately $60 \%$ and $80 \%$ of our cohort needed respiratory and nutritional support, respectively. 56 of our patients (41\%) had a tracheostomy. Amarri et al. reported very recently that $9 \%$ and $11 \%$ of their cohort needed tracheostomy and mechanical ventilation in their cohort (13). Feudtner et al. reported tracheostomy rate as $10.1 \%$ and mechanical ventilator rate as $8.5 \%$ in their multi-center prospective

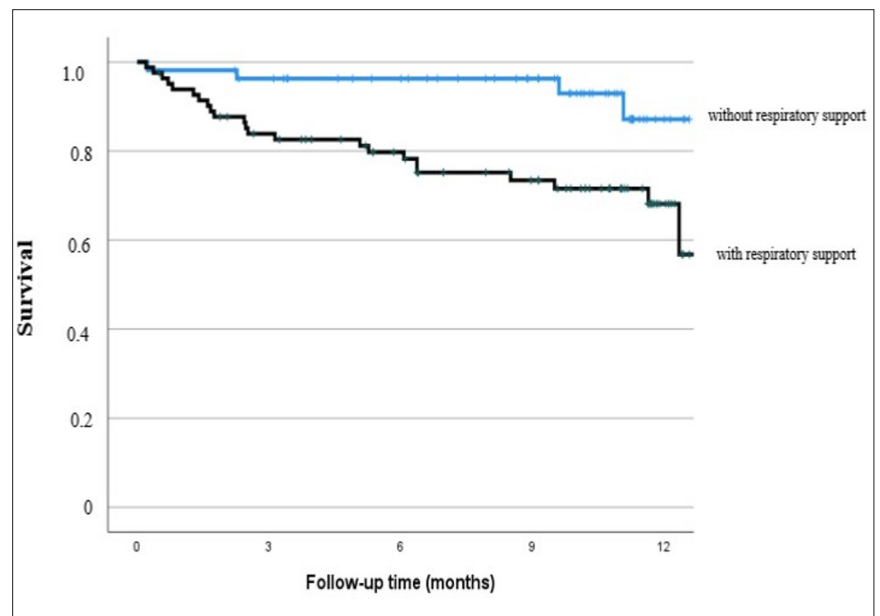

Figure 2B. Kaplan-Meier Survival curve of the 136 patients classified according to respiratory support. Patients with respiratory support had significant worse survival than patients without respiratory support. 
study (8). The high rate of medical technology dependence in our cohort may be the result of the lack of legal basis of withhold or withdraw life support treatments in Turkey (16). In terms of cultural, religious and social aspects end-of-life (EOL) decisions are sensitive and challenging (17). Western countries have improved the EOL concept and they have established its ethicolegal framework (18, 19). New aspects and discussions about EOL concept are urgently needed in Turkey, as well.

Half of the patients in our cohort were referred to PPC center from ED. The core reason for ED admission was the respiratory symptoms. Children with multiple CCC and neurological impairment, together with the use of technological devices are known to have higher access to health services (20). It was shown that children with chronic conditions comprise a significant portion of annual pediatric ED visits. Additionally, they had increased length of stay at ED and hospital or PICU admission rate (21). The health system of Turkey has some specialties compared to western health systems. There is no ambulatory PPC program in Turkey. Only opportunity for these children is the home health care teams. They are not 24/7 available and not well integrated to palliative care system in Turkey, however. Because of these disadvantages only $24 \%$ of our cohort was followed by home health care service of our hospital. As a result, palliative care is provided by inpatient palliative care centers in Turkey. To date there are approximately 5500 palliative care beds in Turkey, of which only 129 belong to pediatric PPC centers. This low count of pediatric palliative beds shows an important demand on PPC centers in Turkey, since 27.2\% of our population is under 18 years of age (22).

The cause of hospitalization was infections in $58 \%$ of the patients. The patients on PPC are at higher risk for colonization and infections with multidrug-resistant pathogens because of multiple hospital admissions, surgical interventions,frequent antibiotic treatments, presence of long-lasting devices (e.g., gastrostomy tube, tracheostomy), and their underlying condition (23). Acute lower respiratory tract infections can be life threatening in children with CCC (24). Therefore, strict adhering to infection control measures is even more vital in these patients.

Despite the lack of ambulant palliative care centers in Turkey we could discharge to home $86.5 \%$ of our patients with a median 7 days of hospital stay. In a multicenter adult study from our country, the rate of discharge to home was determined as $56.6 \%$ in inpatient palliative care setting (25). Since prognosis, life expectancy and functional outcome often less clear in PPC compared to adult palliative care setting (26), our parents prefer to be at home despite high burden of care work. The available literature shows that patients requiring PPC and their parents prefer to stay at home, but keeping such children at home is not easy to realize $(8,27-29)$. The caregivers must learn the skills needed to manage the young patient and they must improve their ability to handle the medical devices (27). All of this takes a great deal of effort and time. Caring for a child with such complex healthcare needs at home can negatively affect the physical and emotional well-being of parents, siblings and other members of the family (30). Therefore, to keep these children at home new planning in Turkish health care system should be made such as constant presence of trained personnel.

During the 13-month follow-up 27 patients (20\%) died. One-year survival was $78.1 \%$. One-year mortality rate is reported as $30-39 \%$ in the PPC literature $(8,9)$. Mortality rate reaches to $55 \%$ in 5 years in PPC settings (31). Mortality rates at adult PC units were reported to be between 23\% and $78 \%$ in the literature, and the general mortality rate was expected to be $\leq 60-75 \%$ (25). The overall pattern of prolonged survival of patients who received PPC, and their multiple readmissions to hospital, show that PPC centers will provide health care service not only to new patients but also to a large group of established patients who have long surviving. Therefore, appropriate health care staffing for PPC teams needs to account, new as well as the existing patient cases (8). A majority of the deaths occurred in the acute care hospital setting in our study. This is similar to the data presented by Frissola and Feudnter et al. $(8,9)$. They explained their high rate of inpatient death with limited access to ambulant palliative care and inpatient hospice programs. We had no access to ambulant PPC and inpatients hospice programs in our country as well. The differences concerning the place of death may be due to cultural preferences (31). To our knowledge there is no study in our country about the preference of place of death in children with life-limiting chronic condition and their parents. Being younger than 2 years of age and having respiratory support are important risk factors of mortality. These children should be followed up more intensely and their parents should inform about early mortality.

\section{CONCLUSION}

Describing the cohort of patients on PPC provides important information on the complexity of their disease process, types of their illnesses, medical technology dependence, re-admission rates, mortality status and factors affecting mortality. Important research has been done but pediatric palliative care is still in infancy in Turkey. Research examining the needs of both children and their families with life-threatening illnesses is central for the quality of life of these children and their families. Future prospective research is needed to understand the unique challenges of PPC. 


\section{ETHICAL DECLARATIONS}

Ethics Committee Approval: The study was approved by the Dr. Sami Ulus Maternity and Children's Training and Research Hospital Clinical Researchs Ethics Committee (Date: 04.02.2021, Decision No: E-21/02-96).

Informed Consent: Because the study was designed retrospectively, no written informed consent form was obtained from patients.

\section{Referee Evaluation Process: Externally peer-reviewed.}

Conflict of Interest Statement: The authors have no conflicts of interest to declare.

Financial Disclosure: The authors declared that this study has received no financial support.

Author Contributions: All of the authors declare that they have all participated in the design, execution, and analysis of the paper, and that they have approved the final version.

\section{REFERENCES}

1. Bogetz JF, Schroeder AR, Bergman DA, Cohen HJ, Sourkes B. Palliative care is critical to the changing face of child mortality and morbidity in the United States. Clin Pediatr 2014; 53: 1030-1.

2. Feudtner C, Hays RM, Haynes G, Geyer JR, Neff JM, Koepsell TD. Deaths attributed to pediatric complex chronic conditions: national trends and implications for supportive care services. Pediatrics 2001; 107: e99-e.

3. Austin L, Luker K, Caress A, Hallett C. Palliative care: community nurses' perceptions of quality. BMJ Quality Safety 2000; 9: 151-8.

4. Davies B, Collins JB, Steele R, Cook K, Brenner A, Smith S Children's perspectives of a pediatric hospice program. J Palliat Care 2005; 21: 252-61.

5. Good PD, Cavenagh J, Ravenscroft PJ. Survival after enrollment in an Australian palliative care program. J Pain Symptom Manage 2004; 27: 310-5.

6. Johnston DL, Nagel K, Friedman DL, Meza JL, Hurwitz CA, Friebert S. Availability and use of palliative care and end-of-life services for pediatric oncology patients. J Clin Oncol 2008; 26: 4646-50.

7. Temel JS, Greer JA, Muzikansky A, et al. Early palliative care for patients with metastatic non-small-cell lung cancer. N Engl J Med 2010; 363: 733-42.

8. Feudtner C, Kang TI, Hexem KR, et al. Pediatric palliative care patients: a prospective multicenter cohort study. Pediatrics 2011; 127: 1094-101.

9. Frizzola M, Miller EG. Referrals to a new pediatric palliative care team: details of the first 12 months of operation. J Palliat Med 2014; 17: 585-8

10. Fraser LK, Miller M, Hain R, et al. Rising national prevalence of life-limiting conditions in children in England. Pediatrics 2012 . 129: e923-e9.

11. Widger K, Davies D, Drouin DJ, et al. Pediatric patients receiving palliative care in Canada: results of a multicenter review. Arch Pediatr Adolesc Med 2007; 161: 597-602.

12. Benini F, Trapanotto M, Spizzichino M, Lispi L, Pozza LVd, Ferrante A. Hospitalization in children eligible for palliative care. J Palliat Med 2010; 13: 711-7.

13. Amarri S, Ottaviani A, Campagna A, De Panfilis L. Children with medical complexity and paediatric palliative care: a retrospective cross-sectional survey of prevalence and needs. Ital J Pediatr 2021; 47: $1-7$.
14. Koc I, Eryurt MA. The causal relationship between consanguineous marriages and infant mortality in Turkey. J Biosoc Sci 2017; 49: 536.

15. Downing J, Powell RA, Marston J, et al. Children's palliative care in low-and middle-income countries. Arch Dis Child 2016; 101: 85-90.

16. Baykara N, Utku T, Alparslan V, Arslantaş MK, Ersoy N. Factors affecting the attitudes and opinions of ICU physicians regarding end-of-life decisions for their patients and themselves: A survey study from Turkey. PloS one 2020; 15: e0232743.

17. Saeed F, Kousar N, Aleem S, et al. End-of-life care beliefs among Muslim physicians. Am J Hosp Palliat Care 2015; 32: 388-92.

18. Bell D. The legal framework for end of life care: a United Kingdom perspective. Intensive Care Med 2007; 33: 158-62.

19.Vincent J-L. End-of-life practice in Belgium and the new euthanasia law. Intensive Care Med 2006; 32: 1908-11.

20. Cohen E, Berry JG, Camacho X, Anderson G, Wodchis W, Guttmann A. Patterns and costs of health care use of children with medical complexity. Pediatrics 2012; 130: e1463-e70.

21. O’Mahony L, O’Mahony DS, Simon TD, Neff J, Klein EJ, Quan L. Medical complexity and pediatric emergency department and inpatient utilization. Pediatrics 2013; 131: e559-e65.

22.İstatistiklerle Çocuk, 2020 20.04.2021. Available from: https: //data tuik.gov.tr/Bulten/Index?p=Istatistiklerle-Cocuk-2020-37228.

23.Schmidt P, Hasan C, Simon A, Geffers C, Wager J, Zernikow B. Multidrug-resistant bacteria in a paediatric palliative care inpatient unit: results of a one year surveillance. GMS Hyg Infect Control 2020; 15.

24. Burton C, Vaudry W, Moore D, et al. Burden of seasonal influenza in children with neurodevelopmental conditions. Pediatr Infect Dis J 2014; 33: 710-4.

25. Göksel F, Şenel G, Oğuz G, et al. Development of palliative care services in Turkey. Eur J Cancer Care 2020; 29: e13285.

26.WHO. Integrating palliative care and symptom relief into paediatrics: a WHO guide for health-care planners, implementers and managers 2018.

27.Lazzarin P, Schiavon B, Brugnaro L, Benini F. Parents spend an average of nine hours a day providing palliative care for children at home and need to maintain an average of five life-saving devices. Acta Paediatr 2018; 107: 289-93.

28. Elias ER, Murphy NA. Home care of children and youth with complex health care needs and technology dependencies. Pediatrics 2012; 129: 996-1005.

29. Vickers JL, Carlisle C. Choices and control: parental experiences in pediatric terminal home care. J Pediatr Oncol Nurs 2000; 17: $12-21$.

30. Hauer J. Identifying and managing sources of pain and distress in children with neurological impairment. Pediatr Ann 2010; 39: 198-205.

31. Bender HU, Riester MB, Borasio GD, Führer M. "Let's bring her home first." Patient characteristics and place of death in specialized pediatric palliative home care. J Pain Symptom Manage 2017; 54: 159-66. 